\title{
REVIEW THE NEW SYSTEM AND ITS IMPACT ON INTELLIGENT BUILDINGS AND SUSTAINABLE ARCHITECTURE
}

\author{
S. Abbasi ${ }^{* 1}$, R. Zad Hasan ${ }^{2}$ \\ ${ }^{1}$ Architectural engineering graduate student, Department of Architecture, Ahar Branch, \\ Islamic Azad University of Ahar, Iran \\ ${ }^{2}$ Geography and urban planning graduate student, Department of Geography and Planning, \\ Marand Branch, Islamic Azad University, Marand, Iran
}

Published online: 15 February 2017

\begin{abstract}
Among the important trends in contemporary architecture, sustainable architecture is present in three areas: economic, social and environmental issues raised are among the most important in the area of environmental sustainability, reduce consumption of non-renewable resources and renewable energy is Bhybh cost this Nanotechnology is one of the world's Latests technology is the science of controlling matter at the molecular scale Koch is one of the most important strategies for achieving environmental sustainability, and the advantages of smart materials is to use materials that reduces energy consumption and provide optimal comfort for the residents of a large building and complex building intrusion in sustainable design today must respond to the needs of the 21 st century and only with the integration needs in a complex, to be energy efficiency via smart nano-materials, especially through the role color plays How can building material used with materials resistant, lightweight and cheap to produce, and how to use intelligent and self-healing materials in construction Buildings Hvshmnd.dr this paper, the choice of materials and equipment, to review the architecture of the system, along with the need for intelligent buildings and equipment due to the intelligent material, based on human needs in a sustainable architecture we are today .
\end{abstract}

Keywords: nano-architecture, sustainable construction, intelligent

\footnotetext{
Author Correspondence, e-mail: secoular@yahoo.com

doi: http://dx.doi.org/10.4314/jfas.v9i1s.708
} 


\section{INTRODUCTION}

Sustainability is a tool, move or talk is not new, in fact, a clever and wise development, quality of life and an attitude and a different way of thinking and decision-making for product or building is designed in such development should be at the same time the three objectives be considered: firstly, pragmatic aspects of social, economic and ecological interactions improve the quality of public life is the second least harm to the environment Third, according to new Fnavrhay advances economic aspects

Terms such as intelligent, sensitive and adaptable to define the structure and materials used, including sensors and actuators, and the ability to adapt to external stimuli such as bars and provocations dynamic environment with intelligent architecture (gift, 1390, p. 1). This means that your main operating parameters according to need, demand and changing conditions and alter the dynamic intelligent architecture We also like a living system capable of experimenting and use of new user experiences and taking advantage of this feature, dynamics and self-organization is guaranteed

Building as a structure as soon as the computer's ability to learn, be smart. The first intelligent building technology for providing safe and comfortable environment and energy use. The idea of an intelligent building, connection, access, lighting, security, surveillance, remote management and communication that lie ahead. Operating integrity, the ability to take the system to exchange information among themselves. Exchange of information between these systems makes the output data is the final result, without causing any disorder, done. On the other hand the output of information systems or final decision, accountable systems, the appropriate response to the information from various sources to enter the system, are provided. Outputs information systems and decision-makers, most original and most vital component in this type of architecture is known as responsive architecture are

The development and sustainability in the building industry, is considered as a new phenomenon. (Yazdani, 1392, p. 3)

According to forecasts, about $75 \%$ of the world's population living in cities tend to be. The natural resources must be used to provide the facilities needed to maintain process stability. The architecture is clearly one of the greatest aspects of economic activity in a country. For a family, fiscal revenue growth to a kind of tension and asked for the ownership and possession and having a bigger house with a building materials, furniture, and home appliances expensive, create comfortable temperature conditions in the interior spaces of the house leads. Study the role of architects to find solutions to the myriad of designs, we can promise that in the future architects will have a variety of solutions 
The production solution, the use of social tools, economic and physical sciences to analyze the situation and to explore appropriate responses. The production and use of solutions and tools is simply not possible. The technical approach to environmental issues and facts that include measurable air, noise and light level, resource consumption and material that are measurable, pays. The reliance architect to plan the use of new materials and intelligent building system

The aesthetic aspects of the template can be the use of materials is contemporary architecture: light modulators smart glass, metals, stainless steel, aluminum panels, and active and passive measures like double walls and ceilings and shadowing of photovoltaic cells Smart now has become the common language of sustainability around the world

In fact, the architecture is to identify optimal solutions for building design and to apply. When technology can provide any services to any effective climate, the architecture is conducive to stability. (Taghizadeh, 1390, p. 1)

\section{Architecture and sustainable design}

Sustainable design practices in the design of the built environment to create a stable environment, in an attempt to maximize quality of life and comfort with minimal damage to the natural environment that Nbazmnd rational thinking in architecture and other design professionals sustainability in the design process so that the three basic operating environment, economy and society (people), to consider sustainable design typical of the architecture of lasting value is the maximum capacity of the environment for the convenience of the benefit of consumers Seek and clever tools and strategies to be used in the meantime. This type of architecture, not just the construction of a building in a context of what has been done but otherwise fits the scale and location-based designer unified platform to an integral part of it to be converted. (Ahmadi, 1382, p. 3)

Although the provisions of the resolution related to the stability of the overall recommendations and distributed to promote sustainable architecture and architects in 1993 under the definition, design and sustainable architecture with the harvest of issues of Agenda

\section{1, the following designers around the world advises:}

-Qrar Environmental and social sustainability in the professional liability architects

-Tvsh And continued growth in architectural design, procedures, products, services and standards for the use of sustainable architecture

Construction industry Office \& educational staff, employers, students and the public about the importance of sustainable design 
-Tdvyn Policy, government and commercial building codes designed to ensure sustainable usage

Promotion of existing and future elements of the built environment for the design, production and processing, to sustainable design standards. (Objective curls, 1387, p. 7)

\section{Nano technology}

nano-scale structure (Rocco, 1999) In other words, the use of nanotechnology to create materials on a large scale is very small particles (Svrynvr, 2006) Generally nanotechnology deals with the study of materials on the scale of nanometers, a nanometer $m$ one thousandth of a micron, or about 100,000 times smaller than a human hair (M., 1387, p. 22-15) for nanotechnology has wide application in various fields have considered the application of this technology in the construction industry, Engineering and Technology and architecture is effective

\section{About nano-technology and sustainable architecture}

In recent years, rapid progress in nanotechnology, in particular, developments in the construction industry and the environment have been followed. Ganyk by Frank Lloyd Wright architecture of the building structure adjustment based on Qragyry as defined in the wild today in the form of sustainable architecture and new horizons that nanotechnology will be discussed. (Ibid)

Some of the principles that must be met to be considered a building as a sustainable architecture include increased durability and useful life of the building, saving energy and materials, lack of environmental degradation, natural resource protection and building and ... On the other hand, the architectural profession and the building industry is faced with massive huge amount of material actually constitute the core of building materials and their impact on the environment can not be ignored, for example, by taking advantage of technology Scientists have invented nano glass material used in its material can be deposited automatic infected layer attached to the surface of the glass breaks and also can be harmful gases in the air sterilization (M., 1387 , p. 70-61). Nanotechnology coatings phenomenon that brought against scratches, fracture, corrosion-resistant nano-materials that use nanotechnology currency other achievements that reduce power consumption and extend the life of the building as a renaissance of nanotechnology, IT and lubricants known investment flows (Kia Mohammadi, 1391, p. 3) generally come with nanotechnology devices and instruments used in the various sectors and raw material and energy consumption by reducing the possibility of 
effective measures to protect natural resources and environment provide (Janbozorgi, 1389, p. 44) that all this is an effective step towards sustainable development

\section{Nanotechnology applications in architecture}

Given the novelty of the technology in the construction industry, the first to introduce a few examples of the applications of nanotechnology in construction materials paid then used to introduce structures of the materials described above.

\section{Cement and Concrete}

Concrete is one of the most common building materials that are widely used and studies show that the use of nanoparticles will improve the mechanical properties and increase the quality of concrete. For instance, nano-silica improves concrete strength increases the density of the particles of titanium dioxide used to create self- cleaning and disinfecting properties gay and bright white concrete and the concrete (Janbozorgi, 1389, p. 44)

\section{Nano coating}

In recent years, researchers have been able to identify compounds with anti-bacterial properties of these compounds can grow bacteria and fungi, and other pathogens that prevent the use of the substances in materials and ceramic glazed tiles and sanitary their use in public places such as hospitals and pathogenic bacteria prevented the publication of the most important benefits is the use of nano-coatings suitable insulating cover. Factors influencing the corrosion into the coating. Increased resistance to heat transfer, increase resistance to corrosion, abrasion and corrosion and self- cleaning properties of the surfaces (the same)

\section{Nano glass}

Another application of nanotechnology in the construction industry can be noted nanotechnology-based glass including glass nanotechnology applications related to your production can be self-cleaning glass coating energy controllers noted in glasses self-cleaning of titanium dioxide nanoparticles used in the glass with anti-smudge and disinfection are ... glass can reduce energy controller through ultraviolet and infrared and invisible set-crossing and also prevents Inside the building are wasting energy (the) fire-resistant glass from other uses of nanotechnology is in the technology of a layer of nanoparticles of silica inflated and compressed between layers of glass, which is used to produce a hard layer and tarnish resistant leads (Pour Jafari, 1386, pp. 65-62)

\section{Self-cleaning paints}

Other relevant for applications of nanotechnology in the construction industry can be selfcleaning and anti-scratch paint manufacturer's nanostructured self-cleaning anti-scratch paint 
or very hydrophobic nanometer structures and patterns that can be used via sunlight or rain water to be clean and without any cost

\section{Photovoltaic cells}

The conversion of sunlight into electricity through a photovoltaic cell, commonly called a solar cell, but the high cost of production and emission of toxic gases in their manufacturing process to produce voltage fluctuations by changing light and reduce the efficiency of the cells by changing the angle of the light factor which prevents the public welcome them in our country. This is despite the fact that the development of nano-technology and simulated the process of photosynthesis in plants, the new generation of low-cost high-efficiency photovoltaic production

\section{Smart materials}

Intelligent Building a new term for materials and products that have the ability to perceive and process environmental events and react to them (Georgia, 1388, pp. 88-66). In other words, these materials have the flexibility and ability to shape, form, color and your inner energy reversibly in response to chemical or physical effects change the environment. If materials into three groups Msalhghyr intelligent, semi-intelligent and non-intelligent smart materials classified in the first group, the special features are high while semi-intelligent are only able to respond to environmental influences form for once or Smart materials will change shortly, but these changes will be reversible and repeatable, flexible and adaptable smart materials as the materials known and because their particular characteristics with the environmental conditions are set

Variables that affect the physical and chemical stimuli that are presented in smart materials continue to show their own reaction:

1 - visible light and radiation: ultraviolet and visible part of the electromagnetic radiation

2 - Temperature: The temperature change creates a physical system like the human body

3 - pressure: pressure difference created in a region

4 - The electric field: the creation of an electrical charge

5 - The magnetic field: The field around a magnet or a moving electrical charge

6 - chemical environment: the presence of a particular chemical element or compound, like water

\section{Classification of smart materials}

General building materials available, including traditional, natural and artificial, according to their characteristics such as appearance, texture, chemical composition, mechanical and physical properties, environmental impact and are classified (ibid.). The classification of 
smart materials in addition to considering the above features, other properties, in particular, to distinguish intelligent materials of traditional materials is also included (understanding, 2014, Steven 2008)

\section{The use of smart materials:}

The importance of smart materials when specifying Myshvdkh role Nharadrayjad consider compatible systems (gift, 1390). The material basis of other sensor systems, consistent and controlled form. The ultimate goal, building materials or intelligent substances in nature. With the desired properties at the molecular level, we can Abrhvshmnd materials that are able to play the role of intelligent systems. An advanced intelligent building system can also control the immune system, charge transfer, heating, ventilation and HVAC, wind and earthquake loads and measure the anti-vibration systems against external driving forces to operate.

\section{Smart materials can be examined in terms of function in two groups:}

Group 1: Building the changes in its environment, one of its properties (including chemical, mechanical, electrical, magnetic or thermal) without the need for external controller change Group 2: materials and devices by energy from external controller if any other changes to the desired end state

One of the most interesting category of smart materials that are both Group 1 will be considered, with color-changing materials (chromic) is (Masumi, 1390). These materials. Materials can be divided Table 1, in which main characteristics Building Group 1-1-8 according to the conditions and output data is presented

Table 1: Classification of materials with the ability to change color

Energy output of the input type of smart materials

Changing the color temperature change Trmvkrvmyk

Changing the color of light changes photochromic

CHANGE COLOR voltage electrochromic

Changing color liquid crystal electric current disorder

\section{The definition of intelligent building :}

In total intelligent building, building strong relationships is equipped with an infrastructure that can continuously variable positions relative to their environment and react, adapt, and also allows building occupants to use the resources available to use more effectively and enhance the security and safety of the current cost of a building is usually a large overhead costs for businesses and residents of the building and it can play a major role on the profitability. In addition, many organizations in the world to save energy consumption and improve the working environment and their lives turne 
No longer discuss the issue of intelligent buildings has been raised in public circles. The definition of an intelligent building as this is "an intelligent building construction, which includes a cost-effective dynamic environment by integrating the four main elements of the system, structure, services, management and the relationship between them is . "German scientists "intelligent building" has been defined: "Building that uses the latest technologies used" By definition it is clear that they are building intelligent building systems are updated, they have. Although innovation in intelligent building is important, but this does not mean that necessarily the exchange of information and integration of intelligent building systems makes it Myshvdkh call (Taghizadeh, 1390, p. 1)

\section{Products - Intelligent nanotechnology:}

With the development of nanotechnology and materials, especially with the development of nano and molecular sciences in the near future, with amazing effects these substances have on human life and the impact it will close and we will touch ease. Nano-particles at the molecular scale has tried to ease restrictions

\section{Nanotechnology architectural design:}

In the biggest projects for the environment, will be very, very small (Silberg, 1380). Small projects proposed in the context of nanotechnology and its impact on the human environment can be expected to be in three stages: First, nanotechnology plays a role in architectural design today

Nano-structured materials engineering number is now available for architects and builders

There used in buildings, the transformation of buildings with the use of these materials has been much discussed

Some examples of products that are in development, including thin layer and a transparent protective scratch-resistant windows and automatically receive the ultraviolet radiation of the sun and rain to clean the glass that your color reduction or an increase in ambient temperature, changes and ambient light and resistant concrete bumps and cracks, are, and despite the fact that they are expensive and not yet reached mass production, in some buildings, to For example, in the National Building Standards and Technology in Maryland, America, have been used. Second, look beyond, you've got to try today nanotechnology specialists in 15 to 20 years there will be a good example of it is the strength and flexibility of carbon nanotubes for buildings brings a unique and tips to create new forms, new functions Vtaz'h and communication between people, buildings and the environment promises

And third, in the distant horizon we can see that the pervasive impact of nanotechnology on human life and his relationship with the surroundings and buildings will be inevitable and 
unthinkable. Skin protection against sun, invisible wall and a copy of the germ, are all within the realm of possibility. Changes in social, ethical and environmental apart of this evolution, will not

\section{Intelligent building management system :}

Intelligent building management system using the latest technology it is trying to perfect condition, along with energy efficiency in buildings create Vrd.ayn systems also control different parts of the building and create a suitable environment at the same time providing an cause energy efficiency, the effectiveness and efficiency of the systems and facilities in the building. Control and access to the system using software from anywhere inside the building and out of it via the Internet is possible

\section{CONCLUSION}

The concept of sustainable architecture implies balance and interaction between the three main areas: socio-cultural, economic, political and physical environment encompasses. This more balanced relationship between architecture and architectural work more symbiotic interaction with the environment and more aware of their benefit to the environment was established and in its architecture, materials and resources available, more than wasting or ignoring their needs with efficiency More used. Agnvn pattern as the most important target architecture, and reduce energy consumption and preserve natural resources for future generations, from the most basic necessary measures to

To achieve it. Sustainable architecture architectural solutions for human life and the preservation of its present and future use of homogeneous materials with the environment and local materials as much as possible, minimum fuel consumption and maximum use of solar power with maximum efficiency and minimum environmental degradation and promotion the maximum in terms of physical and psychological recovery and comfortable living environment is discussed

In this paper, it was considered that the effect of nano-materials to improve the quality of architectural spaces Zhrdakhth. The aim of the materials at the nanoscale, obtain a new classification of building materials with high performance. Since the goal of sustainable architecture, energy saving and reduce the use of non-renewable resources, strengthen and increase the life of the building, reducing environmental pollution and reduce costs is due to the fact that today the development of nanotechnology and new ways of making things with lower costs and provide better quality and durability, and low energy consumption also makes it so effective step towards sustainable development goals is Zhyshbrd 
Smart materials are almost endless power, it can change in response to the surrounding environment so that natural materials (Ghyrhvshmnd) to the Nystnd.n are capable of positive change in the architecture, construction and way of life, but important They are most effective in terms of energy, which is why the most important issues Zhysh century. Using smart materials in the building can be used to optimize the energy consumption, because as it was most of materials and products discussed in this article to directly or indirectly take their energy from the environment. In fact, smart materials capable of modifying the increasing global demand for energy resources and raw materials are expensive. Therefore, the use of smart materials saves energy and is therefore sustainable buildings

Tahy costs and implementing a green roof should be compared with the cost of a conventional roof, but the costs are staggering compared to the pollution of air, water and the environment, disease and death caused by this pollution, personal injury social and occurs due to the lack of green space in the built environment. Running costs of fossil fuels, due to the unpleasant effects of deep psychological and spiritual of cities, the problems of floods and flood and surface water control costs, the cost of insulation and perform multiple roofs traditional black should be added to the above costs

Green Roof despite obstacles such as high administrative costs installation, irrigation and maintenance, in a word, economic issues, as a solution Akvzhyk and environmental advantages, has the potential for many applications Using this system in cities reduce energy consumption and to increase environmental efficiency. Green Roof new places to communities inside and outside the house provides space workflows

\section{REFERENCES}

1 - moonlight, brought and colleagues. Intelligent Building facade; stable in architectural approach tomorrow, Proceedings of the Second Conference on Sustainable Architecture, 1390 2 - Ahmadi, F. Sustainable architecture, village, Year 13, No. 40 and 41, 1382

3 -objective process, as, the delivery of humanitarian and environmental theory and its role in the development of basic knowledge of architecture, the idea of a 1, Proceedings of the interdisciplinary City and Urban Development, the Center for Studies and Research Department of Housing and Urban Development and Architecture Urban Development, 1387. 4 - Yazdani, M., smart buildings and architecture, 1392

5 - Taghi-Zadeh, K., sustainable development, sustainable architecture and building industry, Tehran University School of Architecture 1390, 
6 - Lymt, Silberg, Antoine, Philip, Snyder, James Global Technology Revolution: global trends in biotechnology, nanotechnology, information technology, materials and technology Gharaie of 2015, the Publications Committee nanotechnology Policy Studies, Tehran. 1380 7 - Roco, Mc, Williams, RS, .and Alivistos, p. (1999). Nanotechmology research Directions: IWGN Workshop report, Committee on Technology, Interagency Working Group on Nanoscience, Engineering and (IWGN), National Science and technology Council.

8 - Mann, surinder (2006). Nanotechnology and Construction, European Nanotechnology Gateway.

9 - Mahmoud M, H Siddique ZM Side. The use of nanotechnology in the field of architecture in line with the objectives of green architecture, architectural thinking Magazine, Issue 17, pp. 15-22, 1387.

10 - Mahmoud M., recovery Mohammad Hadi Sadiq H. ZM Side. The Role of the Environment, Volume I, Volume III, pp. 61-70, 1387.

11 - Mohammad Kia M, the character May. Nanotechnology and its role in hardened concrete properties, the first National Conference on ideas and new technologies in architecture, Tabriz, 1391.

12 - life is great, the confectioner. The application of nanotechnology in the construction industry, quarterly Kayson, new era, No. 44, 1389.

13 - Pourjafari Mohammed Assadi May. The impact of nanotechnology on the improvement of building materials, monthly construction project management, architecture and urbanism, Issue 45, Page 62

How to cite this article:

Abbasi S, Zad Hasan R. Review the new system and its impact on intelligent buildings and sustainable architecture. J. Fundam. Appl. Sci., 2017, 9(1S), 500-510. 